\title{
Nitrogênio e Métodos de Semeadura no Rendimento da Forragem de Pós-Colheita de Sementes de Milheto [Pennisetum glaucum (L.) R. Br.] ${ }^{1}$
}

\author{
Eduardo Eustáquio Mesquita², José Cardoso Pinto ${ }^{3}$
}

\begin{abstract}
RESUMO - Um experimento de campo foi realizado para avaliar o efeito de doses de nitrogênio (N) (0,60,120 e $180 \mathrm{~kg} / \mathrm{ha})$ e métodos de semeadura (a lanço; 0,40; 0,80; e 1,20 m entre linhas) sobre o rendimento de matéria seca (RMS), a densidade de perfilhos e os teores de proteína bruta (PB) e minerais ( $\mathrm{P}, \mathrm{K}, \mathrm{Ca}$ e $\mathrm{Mg}$ ) do material de pós-colheita de sementes de milheto. O delineamento experimental foi blocos ao acaso com os tratamentos dispostos em parcelas subdivididas, alocando-se os métodos de semeadura nas parcelas principais e as doses de $\mathrm{N}$ nas subparcelas. As doses crescentes de $\mathrm{N}$ influíram no RMS, rendimento de PB (RPB), número de perfilhos totais $/ \mathrm{m}^{2}$ (NPT) e teor Mg na matéria seca (MS) da forragem, porém as respostas variaram conforme o método de semeadura. Maiores RMS e NPT foram observados no método de semeadura com 0,40 m entre linhas. O maior RMS ( $8872 \mathrm{~kg} / \mathrm{ha})$ foi obtido com a dose de $120 \mathrm{~kg} /$ ha de $\mathrm{N}$ e o maior RPB $(688,8 \mathrm{~kg} / \mathrm{ha})$, com a dose de $180 \mathrm{~kg} / \mathrm{ha}$ de $\mathrm{N}$. No método de semeadura com 0,80 m entre linhas, os teores de Mg na MS de milheto aumentaram de forma quadrática, em resposta às doses de $\mathrm{N}$, enquanto no método de semeadura com 1,20 m entre linhas a concentração do mineral aumentou linearmente.
\end{abstract}

Palavras-chave: composição mineral, densidade de perfilhos, espaçamento entre linhas, produção de matéria seca, proteína bruta

\section{Nitrogen Levels and Sowing Methods on Forage Yield Produced after Harvesting of Millet Seed [Pennisetum glaucum (L.) R. Br.]}

\begin{abstract}
A field trial was carried out to evaluate the effect of nitrogen (N) levels $(0,60,120$ e $180 \mathrm{~kg} / \mathrm{ha})$ and sowing methods (broadcast and $.40, .80$, and $1.20 \mathrm{~m}$ between rows) on dry matter yield (DMY), tiller densities and crude protein content, and minerals $(\mathrm{P}, \mathrm{K}, \mathrm{Ca}$ and $\mathrm{Mg}$ ) of the material of post harvesting of the millet seed. A completely randomized block experimental design with the treatment in a split plot arrangement was used, with the sowing methods on the main plots and $\mathrm{N}$ doses on split-plots. The increasing $\mathrm{N}$ levels affected the DMY and crude protein yield (CPY), number total of tillers (NTT), and Mg content of the forage dry matter (DM). However, the response changed according to the sowing methods. The highest DMY and NTT were observed in sowing methods with $0.40 \mathrm{~m}$ between rows. The highest DMY ( $8872 \mathrm{~kg} / \mathrm{ha})$ was observed with $120 \mathrm{~kg} \mathrm{~N}$ applied, and the highest CPY (668.8 kg/ha), with $180 \mathrm{~kg} / \mathrm{ha} \mathrm{N}$. In the sowing method with $0.80 \mathrm{~m}$ between rows the $\mathrm{Mg}$ contents in the millet DM quadraticly increased, while in the sowing methods with $1.20 \mathrm{~m}$ between rows the concentration of the mineral linearly increased.
\end{abstract}

Key Words: crude protein, dry matter yield, mineral composition, row spacing, tiller density

\section{Introdução}

No processo de produção de sementes de plantas forrageiras, o material de pós-colheita de sementes pode constituir-se em alimento alternativo para o rebanho. Entretanto, produções elevadas de matéria seca (MS) com teores protéicos satisfatórios somente são obtidas com níveis adequados de fertilidade do solo e práticas culturais corretas.

Entre os principais nutrientes, o nitrogênio $(\mathrm{N})$ destaca-se como essencial, pois proporciona maior perfilhamento e produção e, quase sempre, melhora a qualidade da forragem produzida.
O N é reconhecidamente um nutriente facilmente lixiviado no solo. Nesse sentido, as pesquisas devem buscar estabelecer doses adequadas desse nutriente, aliadas a práticas agronômicas, como, por exemplo, o plantio adensado, que proporcionem altos rendimentos de MS de boa qualidade.

LAL et al. (1992), em trabalho com milheto na Índia, verificaram que a maior produção de MS $(5300 \mathrm{~kg} / \mathrm{ha})$ após a colheita de sementes foi obtida com a dose de $80 \mathrm{~kg} / \mathrm{ha}$ de $\mathrm{N}$. Com doses elevadas de $\mathrm{N}$, a produção de forragem pode decrescer em decorrência do desbalanço de nutrientes. LAL (1979) obteve maior rendimento de MS de milheto com a

\footnotetext{
${ }^{1}$ Parte da dissertação apresentada à UFLA pelo primeiro autor como um dos requisitos para obtenção do título de "Magister Scientiae".

2 Estudante do curso de Doutorado do DZO-UFV. E.mail: mesquita@alunos.ufv.br

3 Professor do Departamento de Zootecnia da UFLA. Bolsista do CNPq. E.mail: josecard@ufla.br
} 
dose de $120 \mathrm{~kg} / \mathrm{ha}$ de $\mathrm{N}$, porém a dose máxima, $180 \mathrm{~kg} / \mathrm{ha}$, proporcionou decréscimo na produção.

$\mathrm{O}$ aumento da produção de MS de sorgo frente às doses de $\mathrm{N}$ é ocasionado pelo maior perfilhamento e pela maior altura de plantas (PATEL et al., 1992). Esta observação foi feita anteriormente por JUNG et al. (1964), em capim-sudão (Sorghum sudanense (Piper) Stapf), os quais atribuíram ao maior perfilhamento provocado pela alta dose de $\mathrm{N}$ (333 kg/ha) a mais alta produção de MS.

De maneira geral, os trabalhos conduzidos têm demonstrado que a aplicação de $\mathrm{N}$ eleva os teores de PB da forragem (JUNG et al., 1964; SCHEFFER, 1991; PINTO, 1982; e ROSA, 1984). Por outro lado, PATEL et al. (1992) não encontraram aumento significativo no teor de PB de sorgo com o incremento das doses de $\mathrm{N}$.

Além do N, o plantio com espaçamentos reduzidos entre linhas pode contribuir para aumentar a produção e a qualidade da forragem. Segundo HUMPHREYS e RIVEROS (1986), altas densidades de plantas normalmente aumentam a produção de forragem. BATIONO et al. (1990), na Nigéria, verificaram que a produção de MS de milheto aumentou em $61 \%$, quando se elevou a densidade de plantas de 15.000 para 120.000 plantas/ha. Ficou assim evidenciado que o aumento no número de plantas/ha, em razão da redução do espaçamento, proporcionou maiores produções, particularmente no ano em que ocorreram chuvas intensas no período inicial da cultura, promovendo o rápido crescimento das plantas.

Quando se comparam os métodos de semeadura a lanço e em linhas, verifica-se superioridade deste último quanto à produção de MS (BURGER e CAMPBELL, 1961). Esses autores associaram a maior produção de MS de capim-sudão ao maior perfilhamento das plantas.

Na Califórnia, WORKER JR. (1973) obteve maiores produções de MS de capim-sudão no espaçamento reduzido $(0,36 \mathrm{~m})$, quando comparado com o espaçamento de $0,89 \mathrm{~m}$, tanto para o estádio vegetativo quanto para o reprodutivo, sugerindo assim que, no estádio de pós-colheita de sementes, a produção de MS teria comportamento semelhante. Para 0,$36 ; 0,53 ; 0,71$; e $0,89 \mathrm{~m}$ entre linhas, os teores de PB foram, respectivamente, de 12,3; 12,9; 13,1; e $14,4 \%$ no estádio vegetativo e no reprodutivo, de 8,0 ; 7,$5 ; 8,0$; e $7,1 \%$ para os respectivos espaçamentos. Já o rendimento de PB ( $\mathrm{kg} / \mathrm{ha})$ tendeu a decrescer com o aumento do espaçamento. Outros autores (HART e BURTON, 1965; LIRA et al., 1976) têm comprovado os aumentos na produção e nos teores de PB da forragem de milheto, quando se adota o espaçamento reduzido, porém este fato ocorre quando a precipitação é acima da normal, o que favorece o aproveitamento do $\mathrm{N}$ com o adensamento da cultura.

A composição mineral da forragem de milheto pode variar em função do estádio de desenvolvimento e dos órgãos da planta. STOBBS (1975) encontrou nas folhas de milheto em estádio vegetativo teores de $0,32 \%$ de $\mathrm{Ca}, 0,19 \%$ de $\mathrm{P} ; 4,44 \%$ de $\mathrm{K}$ e $0,21 \%$ de $\mathrm{Mg}$. Nos caules, os teores foram de $0,25 \%$ de $\mathrm{Ca}$ e $0,20 \%$ de $\mathrm{P} ; 5,93 \%$ de $\mathrm{K}$ e $0,25 \%$ de $\mathrm{Mg}$. Nas inflorescências, $0,10 \%$ de Ca e $0,29 \%$ de P; $1,20 \%$ de $\mathrm{K}$ e $0,19 \%$ de $\mathrm{Mg}$.

Respostas às doses de $\mathrm{N}$ e aos métodos de semeadura devem ser analisadas levando-se em conta a disponibilidade de água, a densidade de perfilhos e o teor de matéria orgânica do solo.

\section{Materiais e Métodos}

O trabalho foi conduzido em área experimental do Departamento de Zootecnia da UFLA, Lavras-MG, para estudar o efeito de doses de $\mathrm{N}$ e os métodos de semeadura sobre a produção e a qualidade da forragem de milheto [Pennisetum americanum (L.) Leeke] após a colheita de sementes. O experimento foi estabelecido em um latossolo roxo argiloso, apresentando a seguinte composição química: $\mathrm{pH}$ em água, 5,2; P, 3 e K, 28 mg/dm ${ }^{3}$; Ca, 2,9; Mg, 0,6; Al, 0, 1; H $+\mathrm{Al}, 4,0$; soma de bases trocáveis, 3,6 e CTC efetiva $3,7 \mathrm{cmol}_{\mathrm{c}} / \mathrm{dm}^{3}$; saturação de bases, 47,5 e matéria orgânica, $4,3 \%$.

O delineamento experimental utilizado foi o de blocos casualizados, sendo os tratamentos dispostos em um esquema de parcelas subdivididas, com quatro repetições. Os tratamentos estudados foram quatro doses de $\mathrm{N}(0,60,120$ e $180 \mathrm{~kg} / \mathrm{ha})$, sob a forma de sulfato de amônio, e quatro métodos de semeadura (a lanço; 0,40; 0,80; e 1,20 m entre linhas). Nas parcelas principais foram distribuídos aleatoriamente os métodos de semeadura e nas subparcelas, as doses de N. Com exceção da semeadura a lanço, as subparcelas foram constituídas por seis linhas de $6,0 \mathrm{~m}$ de comprimento e largura variável em função dos espaçamentos. As dimensões e áreas, total das parcelas e total e útil das subparcelas, estão apresentadas na Tabela1.

Os valores médios mensais de temperaturas máximas, mínimas e médias, bem como a precipitação média no período experimental, encontram-se na Tabela 2. 
Rev. bras. zootec.

Tabela 1 - Dimensões das parcelas e subparcelas, em função dos métodos de semeadura

Table 1 - Size of plots and split-plots on the seeding methods

\begin{tabular}{|c|c|c|c|c|}
\hline $\begin{array}{l}\text { Método de semeadura (m) } \\
\text { Seeding methods }\end{array}$ & $\begin{array}{l}\text { Dimensão das } \\
\text { parcelas }(\mathrm{m}) \\
\text { Size of plots }(\mathrm{m}) \\
\end{array}$ & $\begin{array}{c}\text { Área total } \\
\text { parcelas }\left(\mathrm{m}^{2}\right) \\
\text { Total area of plots }\left(\mathrm{m}^{2}\right)\end{array}$ & $\begin{array}{c}\text { Área total } \\
\text { subparcelas }\left(\mathrm{m}^{2}\right) \\
\text { Total split-plots area }\left(\mathrm{m}^{2}\right)\end{array}$ & $\begin{array}{c}\text { Área útil } \\
\text { subparcelas }\left(\mathrm{m}^{2}\right) \\
\text { Useful area split-plots }\left(\mathrm{m}^{2}\right)\end{array}$ \\
\hline Lanço & $8,0 \times 6,0$ & 48,0 & 12,0 & 4,0 \\
\hline \multicolumn{5}{|l|}{ Broadcast } \\
\hline 0,40 & $9,6 \times 6,0$ & 57,6 & 14,4 & 3,2 \\
\hline 0,80 & $19,2 \times 6,0$ & 115,2 & 28,8 & 6,4 \\
\hline 1,20 & $28,8 \times 6,0$ & 172,8 & 43,2 & 9,6 \\
\hline
\end{tabular}

Tabela 2 - Precipitação pluviométrica e temperaturas médias, máximas e mínimas no período experimental Table 2 - Rainfall and mean of the maximum and minimum temperatures in the experimental period

\begin{tabular}{|c|c|c|c|c|c|c|c|c|}
\hline \multirow{3}{*}{$\begin{array}{l}\text { Meses } \\
\text { Months }\end{array}$} & & & \multicolumn{6}{|c|}{$\begin{array}{c}\text { Temperatura }\left({ }^{\circ} \mathrm{C}\right) \\
\text { Temperature } \\
\end{array}$} \\
\hline & \multicolumn{2}{|c|}{$\begin{array}{c}\text { Precipitação }(\mathrm{mm}) \\
\text { Rainfall }\end{array}$} & \multicolumn{2}{|c|}{$\begin{array}{l}\text { Média do ar } \\
\text { Mean of air }\end{array}$} & \multicolumn{2}{|c|}{$\begin{array}{l}\text { Média das máximas } \\
\text { Mean of maximum }\end{array}$} & \multicolumn{2}{|c|}{$\begin{array}{l}\text { Média das mínimas } \\
\text { Means of minimum }\end{array}$} \\
\hline & $\begin{array}{l}\text { Ocorrida } \\
\text { Register }\end{array}$ & $\begin{array}{c}\text { Normal }^{1} \\
\text { Normal }\end{array}$ & $\begin{array}{l}\text { Ocorrida } \\
\text { Register }\end{array}$ & $\begin{array}{c}\text { Normal }^{1} \\
\text { Normal }\end{array}$ & $\begin{array}{l}\text { Ocorrida } \\
\text { Register }\end{array}$ & $\begin{array}{c}\text { Normal }^{1} \\
\text { Normal }\end{array}$ & $\begin{array}{l}\text { Ocorrida } \\
\text { Register }\end{array}$ & $\begin{array}{c}\text { Normal }^{1} \\
\text { Normal }\end{array}$ \\
\hline $\begin{array}{l}\text { Novembro/94 } \\
\text { November/94 }\end{array}$ & 127,4 & 213,0 & 21,9 & 20,9 & 27,9 & 27,2 & 17,5 & 16,6 \\
\hline $\begin{array}{l}\text { Dezembro } \\
\text { December }\end{array}$ & 316,8 & 295,8 & 22,6 & 21,1 & 29,0 & 27,3 & 18,2 & 17,3 \\
\hline $\begin{array}{l}\text { Janeiro } \\
\text { January }\end{array}$ & 200,2 & 272,4 & 23,7 & 21,7 & 30,3 & 27,8 & 18,9 & 17,7 \\
\hline $\begin{array}{l}\text { Fevereiro } \\
\text { February }\end{array}$ & 339,5 & 192,3 & 22,6 & 22,1 & 28,4 & 28,4 & 18,7 & 17,9 \\
\hline $\begin{array}{l}\text { Março } \\
\text { March }\end{array}$ & 124,8 & 174,0 & 22,4 & 20,9 & 28,8 & 27,0 & 18,0 & 17,3 \\
\hline $\begin{array}{l}\text { Abril/95 } \\
\text { April/95 }\end{array}$ & 64,6 & 67,0 & 20,6 & 19,8 & 27,5 & 25,4 & 16,0 & 15,4 \\
\hline
\end{tabular}

${ }^{1}$ Normais - padrão do período de 1965 a 1990 para Lavras - MG.

${ }^{1}$ Normal - standard of period from 1965 to 1990 at Lavras - MG.

De acordo com a análise do solo, foi efetuada uma calagem prévia, em 28/09/94, na dosagem de 2,0 t/ha de calcário dolomítico e na semeadura foi feita a aplicação de $100 \mathrm{~kg} / \mathrm{ha}$ de $\mathrm{P}_{2} \mathrm{O}_{5}$ e $60 \mathrm{~kg} / \mathrm{ha}$ de $\mathrm{K}_{2} \mathrm{O}$, sob as formas de superfosfato simples e cloreto de potássio, respectivamente.

A semeadura foi realizada em 30/11/94, distribuindo-se as sementes no sulco de plantio na semeadura em linhas e, no método a lanço, espalhando-as superficialmente, com leve incorporação à enxada. Observou-se densidade de semeadura de $9,35 \mathrm{~kg} / \mathrm{ha}$ de sementes puras viáveis, para os tratamentos em linhas, e 14,02 kg/ha, para o tratamento lanço.

Parcelou-se a adubação nitrogenada em duas vezes, aos 16 e 36 dias após a semeadura. A aplicação foi feita ao lado das linhas, cerca de $15 \mathrm{~cm}$ destas. No método de semeadura a lanço, o adubo foi aplicado a lanço.

Em 10/04/95, efetuou-se a colheita de sementes da área útil das subparcelas, correspondente às duas fileiras centrais. Consideraram-se duas fileiras de cada lado e $1,0 \mathrm{~m}$ em cada extremidade da linha como sendo as bordaduras. No método a lanço, $0,5 \mathrm{~m}$ de cada margem e $1,0 \mathrm{~m}$ de cada extremidade constituíram as suas bordaduras.

O número total de perfilhos $/ \mathrm{m}^{2}\left(\mathrm{NTP} / \mathrm{m}^{2}\right)$ foi obtido pela contagem de perfilhos em dois metros lineares, ou seja, um metro em cada uma das linhas da área útil para posterior estimativa do NTP $/ \mathrm{m}^{2}$. No tratamento lanço, a contagem foi feita diretamente em $1,0 \mathrm{~m}^{2} \mathrm{da}$ área útil. Posteriormente, obteve-se o número total de perfilhos férteis $/ \mathrm{m}^{2}$, subtraindo-se do 
$\mathrm{NTP} / \mathrm{m}^{2}$ o número de perfilhos vegetativos $/ \mathrm{m}^{2}$.

As plantas foram cortadas ao nível do solo, destacando-se as panículas que se encontravam maduras. As partes remanescentes da planta (caules, folhas, hastes de panículas e panículas verdes) foram pesadas para determinação do peso de matéria verde. Retiraram-se as amostras da forragem (constituídas de três perfilhos representativos da sub-parcela) de póscolheita de sementes, colocando-as em estufa de ventilação forçada a $65^{\circ} \mathrm{C}$ até atingir peso seco constante, obtendo-se assim a amostra seca ao ar (ASA). Em seguida, as amostras secas foram moídas em moinho tipo Willey e acondicionadas em frascos de vidro para posterior determinação do rendimento de MS, proteína bruta (PB) e minerais ( $\mathrm{P}, \mathrm{K}, \mathrm{Ca}$ e $\mathrm{Mg}$ ).

$\mathrm{O} \mathrm{N}$ total da forragem foi determinado pelo método de Kjeldhal, descrito por BREMNER (1965). Os teores de PB foram estimados multiplicando-se o teor de $\mathrm{N}$ encontrado na forragem pelo fator 6,25. As percentagens de $\mathrm{PB}, \mathrm{P}, \mathrm{K}, \mathrm{Ca}$ e $\mathrm{Mg}$ foram corrigidas para MS total determinada a $105^{\circ} \mathrm{C}$. Os minerais $\mathrm{Ca}$ e $\mathrm{Mg}$ foram determinados por espectrofotometria de absorção atômica; o P, por colorimetria; e o K, por fotometria de chama. Foram feitas duas amostras de laboratório para cada uma repetição de campo.

As doses de $\mathrm{N}$ foram desdobradas em seus efeitos linear e quadrático e os métodos de semeadura tiveram as suas médias comparadas pelo teste Tukey a 5\%, dentro de cada dose de $\mathrm{N}$, quando da interação $(\mathrm{P}<0,05)$ métodos de semeadura $\mathrm{x}$ doses de $\mathrm{N}$.

\section{Resultados e Discussão}

A análise de variância revelou significância $(\mathrm{P}<0,05)$ para o efeito de métodos de semeadura e doses de $\mathrm{N}$ sobre o rendimento de matéria seca (RMS) da forragem de pós-colheita de sementes.

$\mathrm{O}$ efeito do nitrogênio sobre o rendimento de MS foi melhor explicado por uma regressão quadrática, $\hat{\mathrm{Y}}=6.607,65+33,27 \mathrm{X}-0,12 \mathrm{X}^{2} ; \mathrm{R}^{2}=0,99 * *$ (Figura 1$)$. $\mathrm{O}$ maior incremento no rendimento de MS ocorreu entre as doses 0 e $60 \mathrm{~kg} / \mathrm{ha}$ de $\mathrm{N}$, sendo menores entre 60 e $120 \mathrm{~kg} / \mathrm{ha}$; acima de $120 \mathrm{~kg} / \mathrm{ha}$, ocorreu ligeiro decréscimo, sendo o valor máximo de rendimento estimado com a dose de $139 \mathrm{~kg} / \mathrm{ha}$.

Respostas quadráticas da produção de MS ao N têm sido demonstradas em vários trabalhos (BROYLES e FRIBOURG, 1959; LAL et al., 1992). Entretanto, POSTIGLIONI et al. (1975) obtiveram aumentos lineares na produção de MS de milheto com doses crescentes de $\mathrm{N}(0,90$ e $180 \mathrm{~kg} / \mathrm{ha})$.

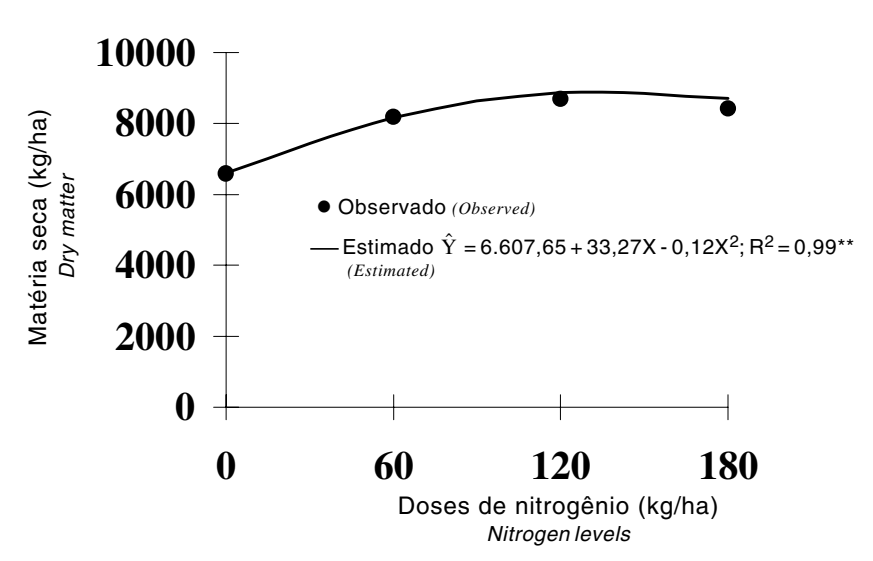

Figura 1- Rendimento de matéria seca em função de doses de N.

Figure 1 - Dry matter yield on $N$ levels.

BROYLES e FRIBOURG (1959) observaram que os maiores incrementos na produção de MS de milheto e capim-sudão foram registrados entre as doses $0 \mathrm{e}$ $67 \mathrm{~kg} / \mathrm{ha}$ de $\mathrm{N}$ e os menores, entre 67 e $135 \mathrm{~kg} / \mathrm{ha}$ de $\mathrm{N}$. Os resultados do presente estudo estão de acordo com os obtidos por esses autores.

O bom rendimento de MS $(6591,8184,8685$ e $8410 \mathrm{~kg} / \mathrm{ha}$ nas respectivas doses $0,60,120 \mathrm{e}$ $180 \mathrm{~kg} / \mathrm{ha}$ de $\mathrm{N}$ ) do material de pós-colheita de sementes, provavelmente, resultou das boas condições pluviométricas e do elevado teor de matéria orgânica do solo. LAL et al. (1992) verificaram que a produção de MS após a colheita de sementes de milheto foi influenciada pelas doses de $\mathrm{N}$ e a maior produção $(5.300 \mathrm{~kg} / \mathrm{ha}$ de MS) foi alcançada com a dose de 80 $\mathrm{kg} / \mathrm{ha}$ de N. Resultados obtidos no presente trabalho são semelhantes aos de LAL (1979), quando a dose média de $\mathrm{N}(120 \mathrm{~kg} / \mathrm{ha})$ proporcionou maior produção de MS em relação a dose máxima $(180 \mathrm{~kg} / \mathrm{ha}$ de $\mathrm{N})$.

No espaçamento de $0,40 \mathrm{~m}$ entre linhas, obteve-se rendimento de MS (9352 kg/ha) estatisticamente igual $(\mathrm{P}>0,05)$ aos registrados na semeadura a lanço $(8071 \mathrm{~kg} / \mathrm{ha})$ e em linhas espaçadas de $0,80 \mathrm{~m}$ (7392 kg/ha). O menor RMS $(\mathrm{P}<0,05)$ ocorreu no espaçamento de $1,20 \mathrm{~m}$ entre linhas $(7056 \mathrm{~kg} / \mathrm{ha})$. A semeadura em linhas espaçadas de $0,40 \mathrm{~m}$ é recomendada, pois favorece a colheita mecânica, ao contrário do método a lanço.

Houve correlação positiva $(r=0,83)$ entre as variáveis RMS e número total de perfilhos $/ \mathrm{m}^{2}\left(\mathrm{NTP} / \mathrm{m}^{2}\right)$. No método de semeadura a lanço, houve acréscimo progressivo do NTP $/ \mathrm{m}^{2}$ com o aumento das doses de N. Esta relação foi melhor explicada por uma regressão 
linear (Figura 2). Já para os métodos de semeadura em linhas, as doses de $\mathrm{N}$ não afetaram o $\mathrm{NTP} / \mathrm{m}^{2}$.

À medida que se reduziu o espaçamento entre linhas, ocorreu acréscimo na densidade de perfilhos (Figura 3). Isto é explicado pelo fato de que, em menores distâncias entre linhas, em uma mesma densidade de semeadura, ocorre menor competição dentro da linha, propiciando maior perfilhamento e resultando em maior RMS. Segundo BATIONO et al. (1990), o aumento da densidade de plantas proporcionou maior produção da forragem de pós-colheita de sementes de milheto, particularmente no ano em que ocorreram chuvas intensas, no período inicial da

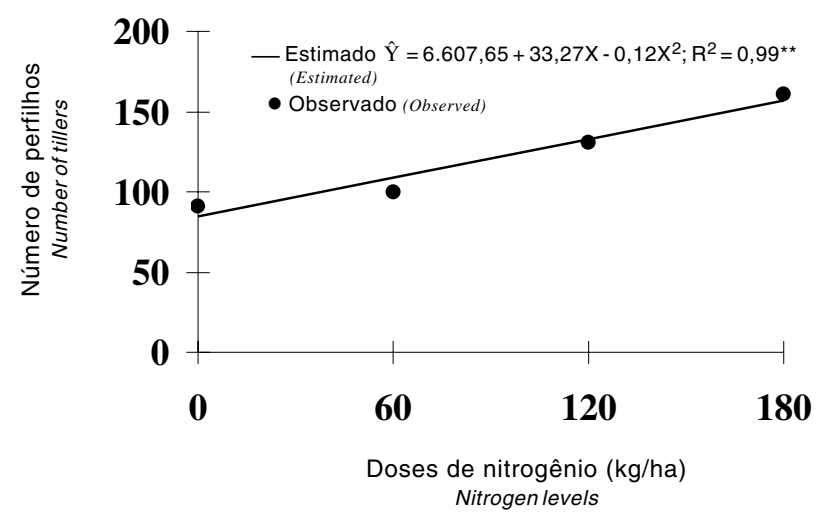

Figura 2 - Número total de perfilhos de milheto $/ \mathrm{m}^{2}$ em função de doses de $\mathrm{N}$.

Figure 2 - Number of tillers total $/ \mathrm{m}^{2}$ on $\mathrm{N}$ levels.

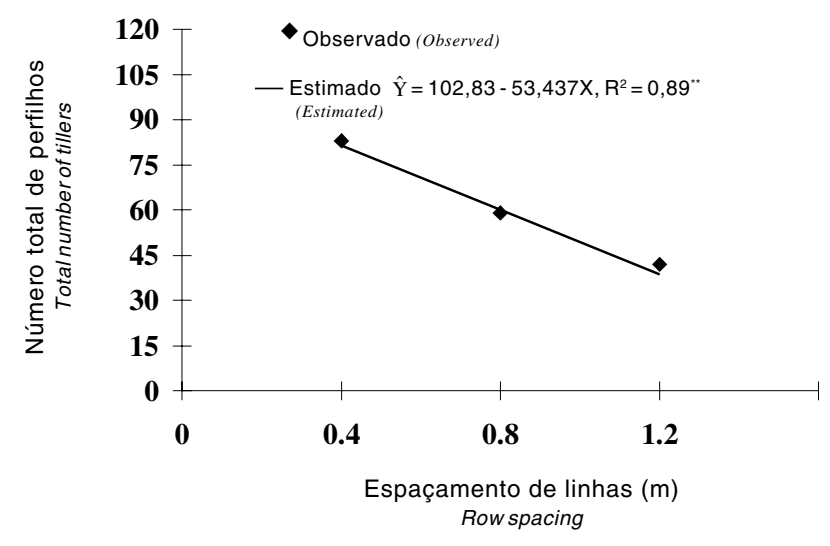

Figura 3 - Número de perfilhos $/ \mathrm{m}^{2}$, em função do espaçamento.

Figure 3 - Number of tillers $/ \mathrm{m}^{2}$ on row spacing. cultura, permitindo o rápido crescimento das plantas. Outros trabalhos têm demonstrado o efeito positivo da maior densidade de plantas no RMS associado ao espaçamento reduzido (BURGER e CAMPBELL, 1961; WORKER JR., 1973; e LIRA et al., 1976).

O maior RMS em espaçamentos reduzidos, em comparação com maiores distâncias entre linhas, foi verificado por McGOWAN et al. (1991) em Sorghum bicolor (L.) Moench, em razão da redução do número de perfilhos nos espaçamentos maiores.

$\mathrm{O}$ rendimento de proteína bruta (RPB) cresceu com as doses de $\mathrm{N}$, segundo a regressão quadrática, $\hat{\mathrm{Y}}=422,44+3,10 \mathrm{X}-0,009 \mathrm{X}^{2} ; \mathrm{R}^{2}=0,99 * *$ (Figura 4). Os teores de PB aumentaram linearmente com as doses de N, variando de 6,0 a 8,0\%, conforme o método de semeadura empregado. Os métodos a lanço e 0,40 e 1,20 m entre linhas são representados pelas respectivas equações de regressão $\hat{\mathrm{Y}}=6,53+$ $0,009 \mathrm{X}, \mathrm{R}^{2}=0,83 * * ; \quad=5,98+0,012 \mathrm{X}, \mathrm{R}^{2}=0,79 * *$ (Figura 5) e $\hat{\mathrm{Y}}=5,77+0,012 \mathrm{X}, \mathrm{R} 2=0,89 * *$.

POSTIGLIONI et al. (1975), trabalhando com doses de 0,90 e $180 \mathrm{~kg} / \mathrm{ha}$ de $\mathrm{N}$, verificaram que os teores e rendimentos de $\mathrm{PB}$ de milheto aumentaram linearmente com as doses de N; no entanto, PATEL et al. (1992) observaram aumentos apenas no rendimento de PB de sorgo.

Na presença de $N$, os teores de $\mathrm{PB}$ não diferiram entre os métodos de semeadura testados $(\mathrm{P}<0,05)$. Com relação ao efeito dos métodos de semeadura sobre o teor de PB na forragem de gramíneas, os dados da literatura são contraditórios. WORKER (1973) verificou que o teor de PB na MS de capimsudão, no estádio de florescimento, tendeu a decrescer com o aumento do espaçamento entre linhas. HART e BURTON (1965) constataram maior teor de PB na MS de milheto em espaçamento maior (0,90 m), no segundo ano; todavia, no primeiro ano, não houve diferença entre os espaçamentos ( 0,18 e $0,90 \mathrm{~m})$. Segundo esses autores, chuvas pesadas provavelmente favorecem a lixiviação de $\mathrm{N}$, principalmente em espaçamento amplo, onde a cultura não teria proporcionado cobertura adequada do solo.

Com relação à concentração de minerais $(\mathrm{P}, \mathrm{K}$, $\mathrm{Ca}$ e $\mathrm{Mg}$ ) no material de pós-colheita de sementes, observou-se efeito significativo de doses de $\mathrm{N}$ apenas sobre o teor de $\mathrm{Mg}$ e a resposta variou conforme o método de semeadura. Os teores de $\mathrm{Mg}$ ficaram entre 0,15 e $0,30 \%$, sendo que para o método de semeadura em linhas espaçadas de $0,80 \mathrm{~m}$ a regressão quadrática foi a que melhor explicou a relação de dependência entre doses de $\mathrm{N}$ e teores de $\mathrm{Mg}$ 


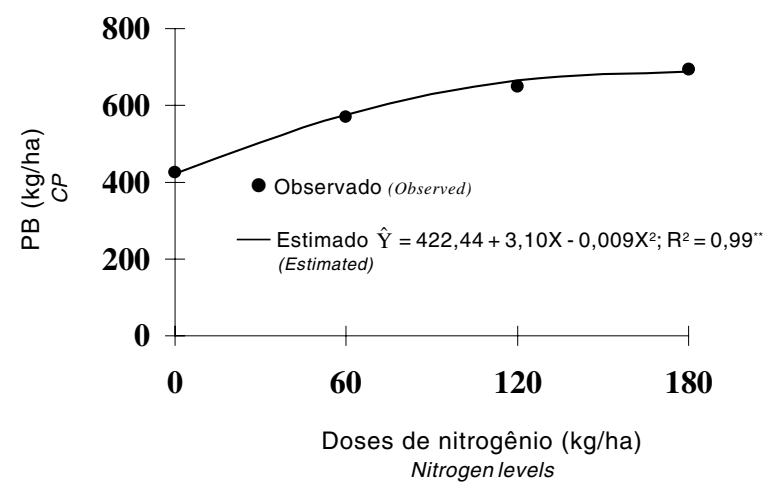

Figura 4 - Rendimento de proteína bruta (RPB) de milheto em função de doses de $\mathrm{N}$.

Figure 4 - Crude protein (CP) yield of millet on $N$ levels.

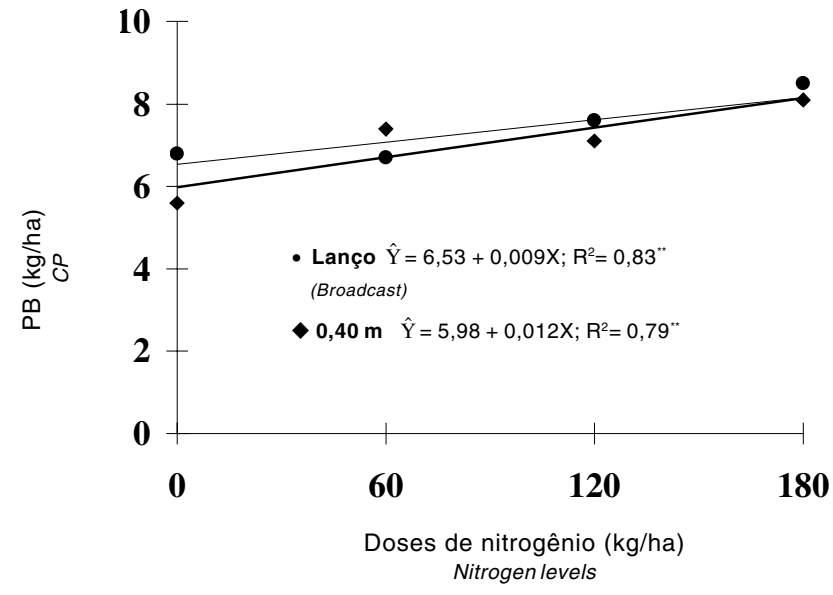

Figura 5 - Teor de proteína bruta (PB) na MS de milheto, em função de doses de $\mathrm{N}$ e métodos de semeadura.

Figure 5 - Percent of crude protein (CP) in DM of millet on $N$ doses and sowing methods.

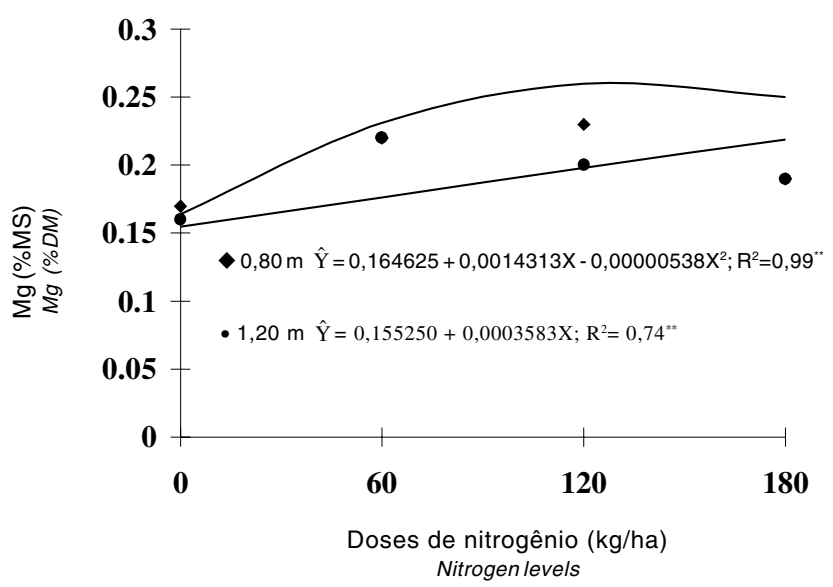

Figura 6 - Teor de magnésio (Mg) na MS da forragem de milheto, em função das doses de $\mathrm{N}$ e dos espaçamentos entre linhas.

Figure 6 - Magnesium content in DM of forage millet on $\mathrm{N}$ levels and rows apart.
( $\left.\hat{\mathrm{Y}}=0,164625+0,0014313 \mathrm{X}-0,00000538 \mathrm{X}^{2} ; \mathrm{R}^{2}=0,99 * *\right)$ (Figura 6). Entretanto, no espaçamento de $1,20 \mathrm{~m}$ entre linhas esta relação foi melhor explicada por regressão linear $(\hat{Y}=0,15525+0,0003583 X$; $\mathrm{R}^{2}=0.74 * *$ ) (Figura 6). MATTOS (1995) verificou que as respostas de $\mathrm{Mg}$ às doses de $\mathrm{N}$ foram lineares e positivas no $2 \underline{\mathrm{o}}$ e $3 \mathrm{o}$ cortes e as suas concentrações médias foram da ordem de 0,$28 ; 0,23 ; \mathrm{e} 0,20 \%$ na MS de milheto, capim-sudão e teosinto (Euchlaena mexicana Schrad.), respectivamente. O teor médio de Mg no presente estudo foi de $0,20 \%$ na MS. Não houve efeito dos métodos de semeadura, das doses de $\mathrm{N}$ e da interação métodos $\mathrm{x}$ doses sobre as concentrações de $\mathrm{P}, \mathrm{K}$ e Ca na forragem. O teor médio de $\mathrm{P}$ foi muito baixo, $0,09 \%$, e os de $\mathrm{Ke} \mathrm{Ca}, 1,60$ e $0,41 \%$ respectivamente.

\section{Conclusões}

Os rendimentos de matéria seca, proteína bruta e teor de proteína bruta do material de pós-colheita de sementes estiveram correlacionados positivamente com a densidade de perfilhos, que variou conforme o espaçamento e suprimento de N. Os maiores rendimentos de MS e PB foram obtidos com a aplicação de $120 \mathrm{~kg} / \mathrm{ha}$ de $\mathrm{N}$ em espaçamento reduzido $(0,40 \mathrm{~m})$.

O material de pós-colheita de sementes de milheto pode ser mais uma fonte de alimento para o rebanho em determinadas regiões, principalmente no período de outono/inverno. Nesse aspecto, os restos da cultura do milheto por ocasião da colheita, de bom nível protéico, 7,18\% PB em média, e boa produção de MS, $7.968 \mathrm{~kg} / \mathrm{ha}$ em média, podem ser incluídos na dieta dos animais, observando-se, porém, a suplementação com fósforo, devido ao baixo teor na forragem.

\section{Referências Bibliográficas}

BATIONO, A., CHRISTIANSON, C.B., BAETHGEN, W.E. 1990. Plant density and nitrogen fertilizer on pearl millet production in Niger. Agron. J., 82(2):290-295.

BREMNER, J.M. 1965. Total nitrogen. In: BLACK, C.A. (Ed.) Methods of soil analysis. Madison: American Society of Agronomy. p.1149-1178.

BROYLES, K.R., FRIBOURG, H.A. 1959. Nitrogen fertilization and cutting management of sudangrass and millets. Agron. J., 51(4):277-279.

BURGER, A.W., CAMPBELL, W.F. 1961. Effects of rates and methods of seeding on the original stand tillering, stem diameter, leaf-stem rates and yield of sudangrass. Agron. J., 53(5):289-291.

HART, R.H., BURTON, G.W. 1965. Effect of row spacing, seedling rate, and nitrogen fertilization on forage yield and quality of Gahi-1 Pearl millet. Agron. J., 57(4):376-378. 
HUMPHREYS, L.R., RIVEROS, F. 1986. Tropical pasture seed production. 3.ed. Rome: FAO. 203p.

JUNG, G.A., LILLY, B., SHIH, S.C. et al. 1964. Studies with sudangrass 1. Effect of growth stage and level of nitrogen fertilizer upon yield of dry matter, estimated digestibility of energy, dry matter and protein. A. Composition and prussic acid potential. Agron. J., 56(6):533-536.

LAL, B., KAUSHIK, S.K., GAUTAM, R.C. 1992. Response of rainfed pearl millet (Pennisetum glaucum) to nitrogen fertilization and moisture conservation. Ind. J. Agric. Sci., 62(7):476-478.

LAL, R. 1979. Effect of nitrogen, phosphorus and potassium on the yield, quality and uptake of N, P and $\mathrm{K}$ of hybrid Bajra. Ind. J. Agron. 25(1):18-24.

LIRA, M. de A., FARIS, M.A., LIRA FILHO, H.P. et al. Experimento de espaçamento e densidade de plantio na cultura do milheto (Pennisetum typhoides) em Pernambuco. In: REUNIÃO BRASILEIRA DE MILHO E SORGO, 11, 1976, Piracicaba. Anais... Piracicaba: ESALQ, 1976, p.825-831.

MATTOS, J.L.S. Comportamento de Pennisetum americanum (L.) Leeke, Sorghum sudanense (Piper) Stapf e Euchlaena mexicana Schrad. sob diferentes regimes hídricos e doses de nitrogênio. Lavras, MG: UFLA, 1995. 96p. Dissertação (Mestrado em Zootecnia)Universidade Federal de Lavras, 1995.

McGOWAN, M., TAYLOR, H.M., WILLINGHAM, J. 1991. Influence of row spacing on growth, light and water use by sorghum. J. Agric. Sci., 116:329-339.

PATEL, P.C., PATEL, J.R., SADHU, A.C. 1992. Response of forage sorghum (Sorghum bicolor) to biofertilizer and nitrogen levels. Ind. J. Agron., 37(3):466-469.

PINTO, J.C. Nitrogênio e métodos de semeadura no rendimento de sementes de Paspalum guenoarum Arech. Porto Alegre: UFRGS, 1982. 140p. Dissertação (Mestrado em Agronomia) - Universidade Federal do Rio Grande do Sul, 1982.
POSTIGLIONI, R.S., JACQUES, A.V.A., BERLATO, M.A 1975. Efeito do nitrogênio sobre o rendimento de matéria seca, teor e produção de proteína bruta da cultivar comum de milheto, sob dois níveis de umidade do solo. Agron. Sulriograndense, 11(1):56-68.

ROSA, J.L. Nitrogênio e métodos de semeadura no rendimento de sementes de Paspalum guenoarum Arech. no segundo ano da cultura. Porto Alegre: UFRGS, 1984. 173p. Dissertação (Mestrado em Agronomia) - Universidade Federal do Rio Grande do Sul, 1984.

SCHEFFER, S.M. Efeito de doses de nitrogênio, métodos de estabelecimento e regimes de corte no rendimento e qualidade da semente e da forragem de milheto (Pennisetum americanum L. Leeke). Porto Alegre: UFRGS, 1981. 131p. Dissertação (Mestrado em Agronomia). Universidade Federal do Rio Grande do Sul, 1981.

STOBBS, T.H. 1975. A comparison of zulu sorghum, bulrush millet and white panicum in terms of yield, forage quality and milk production. Aust. J. Exp. Agric. Anim. Husb., 15(73):211-218.

WORKER JR., G.F. 1973. Sudangrass and sudangrass hybrids responses to row spacing and plant maturity on yield and chemical composition. Agron. J., 65(6):975-977.

Recebido em: 17/03/1999

Aceito em: 09/12/1999 